\title{
Modelagem computacional para avaliação de cenários sobre a reciclagem de papel em uma Instituição de Ensino Superior
}

Flaviani Souto Bolzan Medeiros

Doutoranda no Programa de Pós-Graduação em Administração na Universidade Federal de Santa Maria

flaviani.13@gmail.com

Iliane Colpo

Mestre em Engenharia de Produção pela Universidade Federal de Santa Maria ilicolpo@gmail.com

Glauco Oliveira Rodrigues

Doutorando no Programa de Pós-Graduação em Administração na Universidade Federal de Santa Maria

glaucop10@ redes.ufsm.br

Eugênio de Oliveira Simonetto

Doutor em Administração pela Universidade Federal do Rio Grande do Sul (UFRGS); Professor Adjunto no Departamento de Ciências Administrativas da Universidade Federal de Santa Maria eosimonetto@gmail.com

\section{Editor Científico: José Edson Lara}

Organização Comitê Científico

Double Blind Review pelo SEER/OJS

Recebido em 29.05.2018

Aprovado em 15.11.2018 


\title{
Resumo
}

Cada vez mais se discute iniciativas que visam à preservação do meio ambiente e nessa busca de alternativas à reciclagem se mostra extremamente importante como uma forma de reaproveitamento de materiais que seriam descartados. Dentre os materiais reciclados destacase o papel pela sua representatividade no meio ambiente já que ao reciclar muitas árvores deixam de ser cortadas. Assim, o presente artigo tem como objetivo desenvolver um modelo computacional através da construção de cenários com a finalidade de analisar o quanto pode ser poupado de recursos naturais numa Instituição de Ensino Superior (IES) com a utilização da reciclagem do papel. Para isso, adotou-se um modelo de simulação computacional utilizando a metodologia System Dynamics. Os resultados gerados podem auxiliar a gestão no processo de sensibilização da comunidade acerca da importância da reciclagem demonstrando, de forma quantitativa, o quanto pode ser poupado e/ou desperdiçado de recursos no horizonte de tempo estudado (oito anos).

Palavras-chave: Reciclagem; Instituição de Ensino Superior; Modelagem Computacional; Dinâmica de Sistemas.

\section{Computational Modeling to Evaluate Scenarios on Paper Recycling in a Higher Education Institution}

\begin{abstract}
More and more initiatives are being discussed aiming at preserving the environment and in this quest for alternatives to recycling is extremely important as a way of reusing material that would be discarded. Among the recycled materials, paper stands out because of its representativeness in the environment, since when recycling many trees, they are no longer cut. Thus, the present article aims to develop a computational model through the construction of scenarios with the purpose of analyzing how much can be saved of natural resources in a Higher Education Institution (HEI) with the use of paper recycling. For this, a computational simulation model was adopted using the System Dynamics methodology. The results generated can help the management in the process of raising community awareness about the importance of recycling, demonstrating in a quantitative way how much can be saved and/or wasted resources in the time horizon studied (eight years).
\end{abstract}

Keywords: Recycling; Higher Education Institution; Computational Modelling; System Dynamics. 


\section{Modelado Computacional para la Evaluación de Escenarios sobre el Reciclaje de Papel en una Institución de Enseñanza Superior}

\section{Resumen}

Cada vez más se discuten iniciativas que apuntan a la preservación del medio ambiente y en esa búsqueda de alternativas al reciclaje se muestra extremadamente importante como una forma de reaprovechamiento de materiales que serían descartados. Entre los materiales reciclados destaca el papel por su representatividad en el medio ambiente ya que al reciclar muchos árboles dejan de ser cortados. Así, el presente artículo tiene como objetivo desarrollar un modelo computacional a través de la construcción de escenarios con la finalidad de analizar cuánto puede ser ahorrado de recursos naturales en una Institución de Enseñanza Superior (IES) con la utilización del reciclaje del papel. Para ello, se adoptó un modelo de simulación computacional utilizando la metodología System Dynamics. Los resultados generados pueden ayudar a la gestión en el proceso de sensibilización de la comunidad acerca de la importancia del reciclaje demostrando, de forma cuantitativa, cuánto puede ser ahorrado y/o desperdiciado de recursos en el horizonte de tiempo estudiado (ocho años).

Palabras clave: Reciclaje; Institución de Enseñanza Superior; Modelado Computacional; Dinámica de Sistemas.

\section{Introdução}

O meio ambiente é a condição básica para a existência da vida na Terra, contudo, um dado preocupante vem dos relatórios anuais do Fundo Mundial para a Natureza (WWF, sigla em inglês), a WWF-Brasil (2017) mede o "rastro humano" - chamada de pegada ecológica - a relação entre o consumo e a disponibilidade/regeneração de recursos na natureza. Esse relatório aponta que o planeta precisa de 1,5 ano para regenerar o que consome em um ano, ou seja, a capacidade de utilização é 50\% maior que a capacidade de regeneração.

Lourenço e Lira (2012) ressaltam que o desenvolvimento industrial e tecnológico culminou no uso excessivo dos recursos naturais o que provoca graves problemas socioambientais. Os referidos autores entendem que essa situação fez com que a sociedade reagisse exigindo soluções e mudanças nos sistemas produtivos com o objetivo de preservar o meio ambiente.

Do mesmo modo, Krupp, Silva e Vieira (2017) destacam que a preocupação global com o meio ambiente teve reflexo nas instituições e isso fez surgir políticas de pós-consumo no âmbito legal. Segundo Lagarinhos e Tenório (2013), uma proposta iniciada em 1999 e aprovada em 2010 introduziu a Política Nacional de Resíduos Sólidos que, dentre outras questões, 
determinou que a responsabilidade da gestão dos resíduos fosse compartilhada entre os governos federal, estadual e municípios além de empresas e sociedade.

Uma das formas do tratamento de resíduos se dá pela reciclagem que é um processo que pode amenizar o consumo excessivo de matérias-primas e se torna um caminho em busca do desenvolvimento sustentável. Shibao, Moori e Santos (2010) esclarecem que a reciclagem diz respeito a um conjunto de técnicas que tem como propósito aproveitar os resíduos e reutilizálos no ciclo de produção que eles saíram ou em outro paralelo.

No caso do setor de papel e celulose, além de ser um grande dependente de recursos naturais - como fibras vegetais, energia e água - é também, altamente gerador de resíduos, sendo apontado com uma importante fonte de poluentes tanto do ar como da água e do solo (Miranda, 2008). Retomando o ciclo de responsabilidades, Araújo, Freitas e Rocha (2017) observam que as instituições de ensino superior são especiais, já que além da responsabilidade pelas suas atividades ainda são responsáveis pela geração de conhecimento e pela formação dos profissionais do futuro.

Complementarmente, Vamberto, Lacerda, Silva e Silva (2013) entendem que a busca por novos hábitos sustentáveis é um processo demorado e que as universidades podem ser comparadas a pequenos núcleos urbanos por terem em seu ambiente o desenvolvimento de diversas atividades, operações e integração de diversidades de culturas e convivências entre as partes. Diante do exposto, surge então o problema da presente pesquisa: Quanto de recursos naturais deixaria de ser consumido com a reciclagem do papel?

Deste modo, o objetivo deste artigo consiste em desenvolver um modelo computacional através da construção de cenários com a finalidade de analisar o quanto pode ser poupado de recursos naturais em uma Instituição de Ensino Superior (IES) com a utilização da reciclagem do papel. Para isso, adotou-se um modelo de simulação computacional utilizando a metodologia de Dinâmica de Sistemas para avaliação de cenários de reciclagem de papel em um horizonte futuro de oito anos. Este estudo justifica-se pelo fato da reciclagem ser muito importante para a preservação do meio ambiente (Rossato, \& Sens Neto, 2014; Santos, Galdino, Akabane, \& Santos, 2015), pois ao adotá-la se reduz a quantidade de resíduos descartados (Lopes, 2003; Simonetto, \& Borenstein, 2007), como também, se polui menos o ambiente e faz com que se utilize um número menor de matérias-primas virgens, água e energia (Mello \& Fonseca, 2010). Logo, na visão de Rodrigues e Cavinatto (2003), os saldos positivos ambientais são indiscutíveis. 
Ademais, quanto ao método, Leuck (2008) comenta que via simulações é possível fazer a descrição das consequências de decisões ou de políticas de decisões com base em quais decisões ou políticas possam ser realizadas. Simonetto e Löbler (2014) consideram que o uso de técnicas quantitativas na gestão de resíduos sólidos mostra-se como uma opção viável para o tratamento da complexidade característico ao processo, isso porque por meio da utilização dessas ferramentas é possível ter uma representação do mundo real, analisar seu comportamento e tomar decisões a partir das conclusões extraídas. Portanto, esta pesquisa pode auxiliar na sensibilização sobre a importância da reciclagem, neste caso em específico, através dos resultados obtidos por meio da simulação feita para um horizonte de tempo de oito anos analisando uma IES e investigando o papel para tal finalidade.

Visando atingir o objetivo proposto este trabalho encontra-se organizado da seguinte forma: logo após esta seção de caráter introdutório, consta na seção dois o referencial teórico que embasou o estudo. Em seguida, na seção três, descreve-se a metodologia de pesquisa adotada. Na sequência, a seção quatro remete para a modelagem desenvolvida com a devida exposição dos resultados obtidos. Por último, na seção cinco, apresentam-se as considerações finais acompanhada de sugestões para estudos futuros.

\section{Referencial Teórico}

Esta seção está desmembrada em dois tópicos: no primeiro consta uma breve discussão acerca da gestão ambiental e no segundo segue uma exposição teórica a respeito da reciclagem do papel.

\subsection{Gestão Ambiental}

Meio Ambiente pode ser definido como tudo o que envolve ou cerca os seres vivos, o Planeta Terra com todos os seus elementos, naturais, alterados ou construídos pelos humanos. O homem é parte deste sistema e desde sempre se utilizou dos recursos naturais para sua existência, inicialmente em razão da escala reduzida de utilização e descarte não havia a chamada degradação ambiental (Barbieri, 2007).

No entanto, o equilíbrio inicial entre o meio ambiente e homem foi quebrado, Jacobi (2015) relata que o desenvolvimento econômico e industrial provocou profundas interferências na capacidade de suporte dos ecossistemas do planeta. Do mesmo modo, Barbieri (2007) pondera que a revolução industrial foi um marco da intensificação dos problemas ambientais e 
que o aumento da produção e consumo aliados à crença de que a natureza existe para servir o homem provocaram uma crise ambiental.

Jabbour e Jabbour (2013) recordam que desde 1970 esforços para resolução deste problema vem sendo aplicados, os autores citam a Conferencia United Nations Enviromental como o marco da $1^{\text {a }}$ era de conscientização ambiental. Já na década de 80 grandes acidentes ambientais como o Exxon Valdez e Union Carbid marcaram a $2^{\mathrm{a}}$ era, tendo sido apresentadas as primeiras evidências do aquecimento global. Na década de 90 o tema ganha maior ênfase no sentido de que poderiam existir benefícios mútuos, entre organizações e ambiente, essa considerada pelos autores a $3^{\mathrm{a}}$ era de conscientização. Hoje, o planejamento e a organização têm como objetivo a redução dos impactos ambientais, aproveitando os benefícios associados a esta melhoria.

Falkner (2008) expõe que as crises ambientais são globais e provocam mudanças climáticas e a perda da diversidade biológica, alega ainda, que a globalização da produção, do consumo e do intercâmbio econômico está alimentando a destruição ambiental, ao mesmo tempo em que complica a busca por soluções políticas. Tinoco e Kraemer (2011) complementam que essa crescente e assustadora degradação ambiental faz com que as empresas incorporem aos seus objetivos a responsabilidade social, que abrange o bem-estar da população.

Para Jabbour e Jabbour (2013), ainda que alguns dirigentes organizacionais insistam em desconsiderar os aspectos ambientais durante a prática administrativa, entende-se que a inclusão das preocupações ambientais no dia a dia das organizações classe mundial seja um processo irreversível. Chen (2011) considera que a gestão ambiental alçou um importante patamar dentro das organizações e está se tornando parte crucial da gestão dos negócios.

Assim, a gestão ambiental é considerada como a nova função empresarial e possibilita as empresas tanto avaliarem e corrigirem danos ambientais do presente como evitarem danos futuros (Sanches, 2000). Vários estudos apontam de forma positiva para a relação entre práticas ambientais proativas e um melhor desempenho econômico e ambiental das organizações (Christmann, 2000; Wagner, 2005; Wilson \& Williams; Kemp, 2012; Martín-Peña, DíazGarrido, \& Sanchez-Lopes, 2014).

Martín-Peña, Díaz-Garrido e Sanches-Lopes (2014) entendem que a evolução do desempenho ambiental proporciona melhoria no relacionamento entre as empresas e seus stakeholders. Já Ceruti e Silva (2009) concluem que as principais dificuldades na relação empresa-ambiente são o desprendimento de recursos para a demanda ambiental, seguida do 
relacionamento com os órgãos reguladores e a falta de capacitação pessoal e estrutural das empresas para tratar da área de meio ambiente.

Entretanto, Rosa e Smek (2017) deixam claro que para que as práticas sustentáveis possam acontecer, é necessário que a sociedade esteja engajada, envolvendo tanto o governo, as empresas como os indivíduos de modo geral. Mas, Pereira, Ferraz e Massaini (2014) acreditam que, pouco a pouco, a conscientização vai chegando aos governos, às empresas e aos indivíduos e, assim, as políticas de preservação terão um funcionamento melhor.

\subsection{A Reciclagem do Papel}

Lomasso et al. (2015) explicam que a reciclagem refere-se à operação onde resíduos de produtos que já foram consumidos e objetos que viriam a ser descartados no meio ambiente por serem julgados como inservíveis são recolocados no ciclo produtivo por meio do seu uso como matéria-prima para a fabricação de produtos novos. Em outras palavras, é um processo de valorização de produtos e materiais que após serem utilizados geralmente não conservam intactas as suas funcionalidades, permitindo que alguma parte ou a sua totalidade seja reaproveitada para ingressar novamente na cadeia, como produtos originais ou como inputs para novos produtos (Moura, 2006).

Souza, Paula e Souza-Pinto (2012) salientam que a vida útil de um produto corresponde ao período de tempo entre a sua produção e a ocasião do seu descarte, a partir desse momento, pode haver a extensão da sua vida útil através da reforma, reuso ou via coleta seletiva onde produtos e embalagens na fase pós-consumo são devidamente separados e encaminhados para o processo de reciclagem sendo inseridos de novo no processo produtivo como matéria-prima secundária. Deste modo, pela reciclagem há o reaproveitamento de materiais e ela se aplica a muitos produtos consumidos pela sociedade - itens que estão ou estariam sendo colocados no lixo - e no caso da reciclagem do papel, trata-se do reaproveitamento de fibras celulósicas de aparas e outros papéis utilizados para a manufatura de novos papéis (Ferreira Junior \& Santos, 2014).

Tatoutchoup (2016) lembra que no decorrer das últimas três décadas campanhas têm procurado estimular a reciclagem de papel, pois além de reduzir a poluição e o espaço no aterro tem como principal argumento a preservação das árvores, já que as mesmas geram externalidades positivas, tais como: amenidades diretas, a conservação do solo e o sequestro de carbono. Em adição, entre os benefícios da reciclagem do papel Gauto e Rosa (2013) citam a 
diminuição do consumo de água usada na produção e a redução do consumo de energia, além disso, com a reciclagem deixa-se de cortar árvores - estima-se que de 15 a 20 para cada uma tonelada de aparas (papéis cortados utilizados na reciclagem). Ademais, na Figura 1 os autores apresentam o ciclo simplificado da reciclagem de papel.

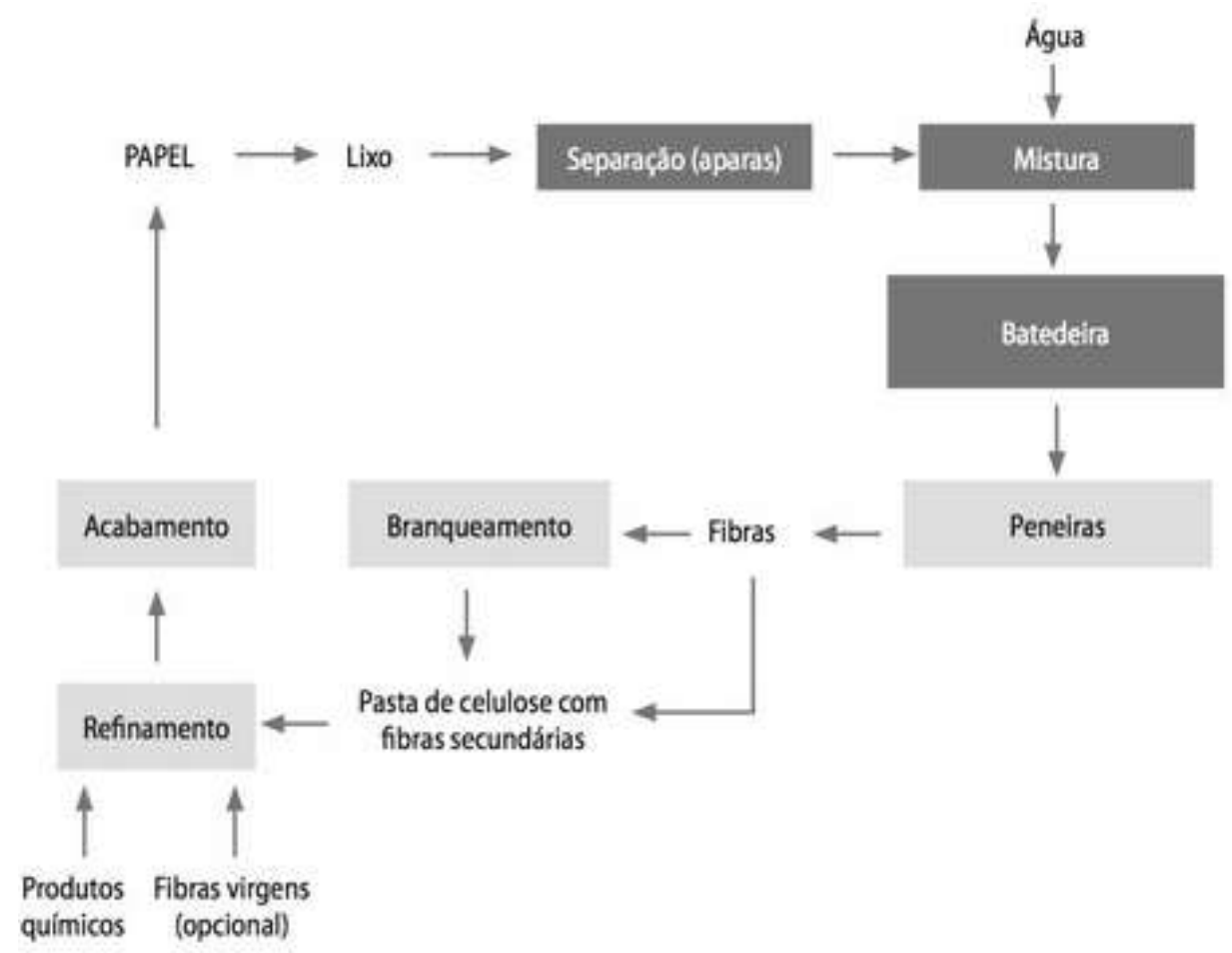

Figura 1: O ciclo de reciclagem do papel.

Fonte: Gauto \& Rosa (2013, p. 206).

Acerca da Figura 1 nota-se que o ciclo de reciclagem do papel começa com o recebimento das aparas, em seguida, passa por um processo para que suas fibras sejam separadas, depois, são acrescentados produtos químicos visando o seu branqueamento, após, dependendo da qualidade do papel que se quer produzir pode vir a ser adicionada celulose virgem, por fim, há o acabamento e o papel estará pronto para o consumo novamente. Segundo Rocha, Rosa e Cardoso (2010), a reciclagem do papel busca produzir papéis, cartões, como também, cartolinas e papelões oriundos de sobras/aparas durante o processo de fabricação e artefatos desses materiais na fase de pós-consumo. Na Figura 2 segue uma listagem dos papéis que podem ou não serem reciclados. 


\begin{tabular}{|l|l|}
\hline \multicolumn{1}{|c|}{ Papéis recicláveis } & \multicolumn{1}{c|}{ Papéis não recicláveis } \\
\hline $\begin{array}{l}\text { Papéis de escrever- cadernos, papéis de escritório em } \\
\text { geral }\end{array}$ & Papel celofane \\
\hline Papéis de impressão - jornais, revistas & $\begin{array}{l}\text { Papéis encerados ou impregnados com substâncias } \\
\text { impermeáveis }\end{array}$ \\
\hline $\begin{array}{l}\text { Papéis de embalagem - papéis de embrulho em geral, } \\
\text { papel de seda, etc. }\end{array}$ & Papel-carbono e papéis sanitários usados \\
\hline $\begin{array}{l}\text { Papéis para fins sanitários - papéis higiênicos, papel } \\
\text { toalha, guardanapos, lenços de papel }\end{array}$ & $\begin{array}{l}\text { Papéis sujos, engordurados ou contaminados com } \\
\text { alguma substância nociva à saúde }\end{array}$ \\
\hline $\begin{array}{l}\text { Cartões e cartolinas - caixas de papelão e cartolinas em } \\
\text { geral }\end{array}$ & $\begin{array}{l}\text { Papéis revestidos com algum tipo de parafina ou } \\
\text { silicone }\end{array}$ \\
\hline $\begin{array}{l}\text { Papéis especiais - papel kraft, papel heliográfico, papel } \\
\text { filtrante, papel de desenho }\end{array}$ & Fotografias e fitas adesivas e etiquetas adesivas \\
\hline
\end{tabular}

Figura 2: Tipos de papéis

Fonte: Instituto Gea (2017).

Contudo, Pereira, Boechat, Tadeu, Silva e Campos (2012) comentam que o papel é um composto de fibras celulósicas de madeira e tem com principais dificuldades para a reciclagem os seguintes fatores, a saber: aparas não homogêneas; bem como a não eliminação das impurezas existentes na massa celulósica que foi recolhida; descarte e tratamento dos rejeitos e resíduos de papel; a complexidade da qualidade dos vários tipos de papéis usados; e ainda, os custos elevados com transporte das aparas e resíduos até os centros que realizam a reciclagem.

\section{Metodologia}

Neste trabalho, o método de pesquisa adotado para o desenvolvimento do modelo computacional foi baseada na metodologia de Dinâmica de Sistemas. A Dinâmica de Sistemas foi criada na década de 50 na Escola de Administração Sloan School of Management do Massachusetts Institute of Technology (Pidd, 2001). Conforme Villela (2005), a Dinâmica de Sistemas tem como finalidade apresentar as seguintes características básicas de qualquer sistema: Relações de Causa e Efeito, Tempos de Resposta e Estoque. Villela (2005) entende que a Dinâmica de Sistemas aliada à modelagem é capaz de expressar de maneira mais adequada e de forma gráfica os complexos eventos presentes na natureza.

A metodologia de Dinâmica de Sistemas se encaixa no objetivo deste artigo, no caso, desenvolver um modelo computacional através da construção de cenários com a finalidade de analisar o quanto pode ser poupado de recursos naturais numa Instituição de Ensino Superior (IES) com a utilização da reciclagem do papel. Ford (2009) afirma que a Dinâmica de Sistemas 
permite o estudo do comportamento de sistemas ao longo de diversos períodos de tempo, permitindo a avaliação das consequências de novas decisões em um horizonte de tempo futuro.

Para o desenvolvimento do modelo computacional utilizou-se quatro etapas. A etapa (I) representa o estudo exploratório em artigos científicos, relatórios técnicos, diálogos com stakeholders e observações do ambiente onde os dados foram coletados. Através desses dados, o problema de pesquisa foi especificado e estruturado. A etapa (II) apresenta o desenvolvimento da solução através da construção do modelo formal capaz de representar o problema (definição das variáveis e seus relacionamentos). A implementação computacional da solução (etapa III), será realizada com o auxilio do simulador Vensim (Ventana Systems, 2016) e, por fim, a etapa (IV) é responsável pela verificação e execução do modelo, através de testes em laboratório e análise do comportamento histórico (com os dados que foram possíveis), para verificar se os resultados obtidos representam parte da realidade observada.

Além disso, foram utilizados dados primários e fontes secundárias. Sendo assim, os dados primários desta pesquisa são constituídos da quantidade de papel que foram requisitados no ano de 2017 pelos vários setores, departamentos e centros do organograma da instituição ao setor de almoxarifado central. Tais dados estão disponíveis no portal gerencial da instituição, no Sistema de Informações Educacionais (SIE).

Quanto aos dados secundários, são compostos por elementos bibliográficos que foram buscados no meio acadêmico, assim, as variáveis que alimentam o sistema se tratam de informações a respeito da quantidade de recursos necessários para a transformação do papel virgem em papel reciclado e o número de árvores para obtenção de papel virgem.

As variáveis encontradas foram redimensionadas em taxas projetadas para este estudo e utilizadas para prospecção dos resultados. Para obtenção dos resultados foi utilizada a metodologia de Dinâmica de Sistemas, criando uma simulação dos possíveis resultados tendo como perspectiva três cenários diferenciados, o primeiro dito atual, seguido de um cenário mediano e otimista. Para realizar uma simulação, segundo Ford (2009), é necessário gerar um modelo computacional. Um modelo computacional de Dinâmica de Sistemas pode ser definido como a estrutura resultante da interação de políticas. Na próxima sessão constam maiores detalhes sobre a modelagem computacional. 


\subsection{Modelagem Computacional}

Rondón, Murakami e Sakaguti (2002) esclarecem que modelagem computacional busca trocar conceitos e conhecimentos pertinentes em equações matemáticas a fim de implementálas através de processos lógicos, simulando casos reais no computador. Complementarmente, Andrade, Seleme, Rodrigues e Souto (2006) acrescentam que a modelagem computacional é considerada um dos artefatos do pensamento sistêmico que adiciona aprendizado ao processo e por meio da mesma constroem-se micromundos do sistema real. Neste artigo foram utilizados dois tipos de modelagem, a modelagem a partir de modelos causais e a modelagem de estoque e fluxo.

Os modelos causais têm o objetivo de criar diagramas que servem para expor uma situação por meio de palavras que constituem os conceitos de um sistema complexo, essas palavras são conectadas por setas que refletem nas influências do sistema. Estes modelos procuram demonstrar as relações de causa e efeito dentro do contexto do problema e sua principal utilidade são para as análises qualitativas. Porém, são os modelos de estoque e fluxo que apresentam as variáveis, os parâmetros e a estrutura do sistema favorecendo as análises quantitativas (Amaral, 2012; Amaral, Gonçalves, \& Hess, 2015).

Madachy (2008) salienta que os modelos computacionais causais e de estoque e fluxo qualificam os modelos mentais, nos quais as decisões são baseadas, e assim, contribuem para a resolução dos problemas. Villela (2005) complementa que os modelos causais representam de forma qualitativa as relações entre as variáveis componentes ao modelo estudado e que representar este mesmo problema de forma quantitativa é necessário ter modelos de estoque e fluxo. Além disso, o mesmo autor revela que os modelos causais têm como principal característica a sua simplicidade, podendo ser um instrumento eficaz para se iniciar a discussão de uma situação-problema. Já no que diz respeito ao modelo de estoque e fluxo, Villela (2005) diz que ele é representado por cinco elementos básicos, os quais podem ser visualizados na Figura 03. 


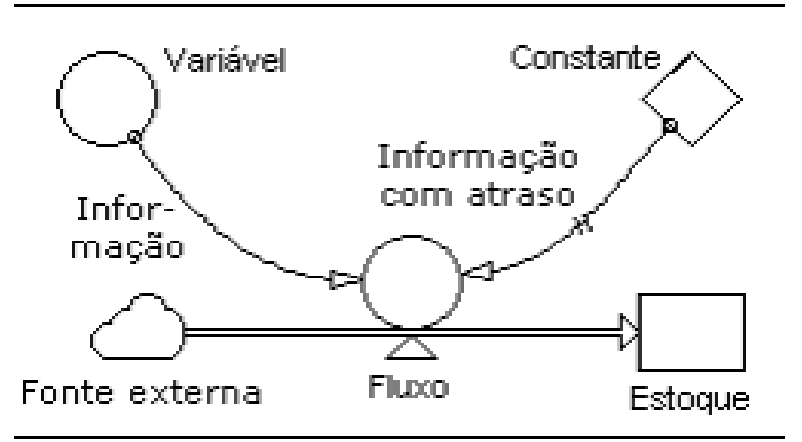

Figura 3: Elementos básicos de um modelo genérico de estoque e fluxo.

Fonte: Villela (2005, p. 9-10).

As variáveis são representadas na Figura 2 por círculos e se referem aos parâmetros que serão utilizados no sistema. Caso uma variável assuma um valor que não se altere será chamada de constante (triângulo) ou altere em um determinado tempo será conhecida como auxiliar. Já os fluxos se referem ao transporte dos recursos no sistema e são medidos em unidade de uma grandeza e por uma unidade de tempo (metros por segundo). Os estoques são as acumulações ou desacumulações dos recursos e seus valores dependem dos fatos passados. As informações são elos que ligam e explicam as relações entre os elementos e o sistema, porém, elas não são capazes de incluir ou excluir estoques, caso apareçam com duplo traço significa que estarão disponíveis no futuro. E, por último, a fonte externa que indica uma fonte de recurso que não interessa ao modelo (Villela, 2005).

\section{Modelagem e Resultados}

Sempre que uma decisão é tomada e se executa alguma ação haverá consequências e estas podem estar dentro do nosso controle ou podem ser consideradas risco ou incerteza. Este artigo está baseado em um amanhã incerto, já que os dados coletados não proverão um futuro certo. De acordo com Pidd (2001), um modelo deve ser fundamentado na análise em alguma escala de tempo predeterminada, onde existe tempo suficiente para tentar avaliar todas as opções de saída do modelo desenvolvido. Assim, o experimento na prática tenderá a se encaixar melhor na realidade. Pidd (2001) também ressalta a necessidade de replicação, ou seja, o modelo deve possibilitar sua aplicação em mais de um ambiente de estudo.

O presente modelo foi desenvolvido utilizando a metodologia de Dinâmica de Sistemas através do software Vensim. Deste modo, a Figura 3 representa a interação entre as variáveis do modelo computacional desenvolvido onde existem seis saídas que servirão como base para 
a análise dos resultados propostos por esta pesquisa e todas são variáveis auxiliares: EnergiaDesperdiçada, ÁrvoresDesperdiçadas, ÁguaDesperdiçada, EnergiaPoupada, ÁrvoresPoupadas, ÁguaPoupada.

O modelo possui três variáveis de estoque ("Qtfolha", "Reciclagem","Descarte",), estes são alimentados por três variáveis de fluxo ("No Pacotes", "Tx Descarte","Tx Reciclagem"). As variáveis estão representadas a seguir na Figura 4.

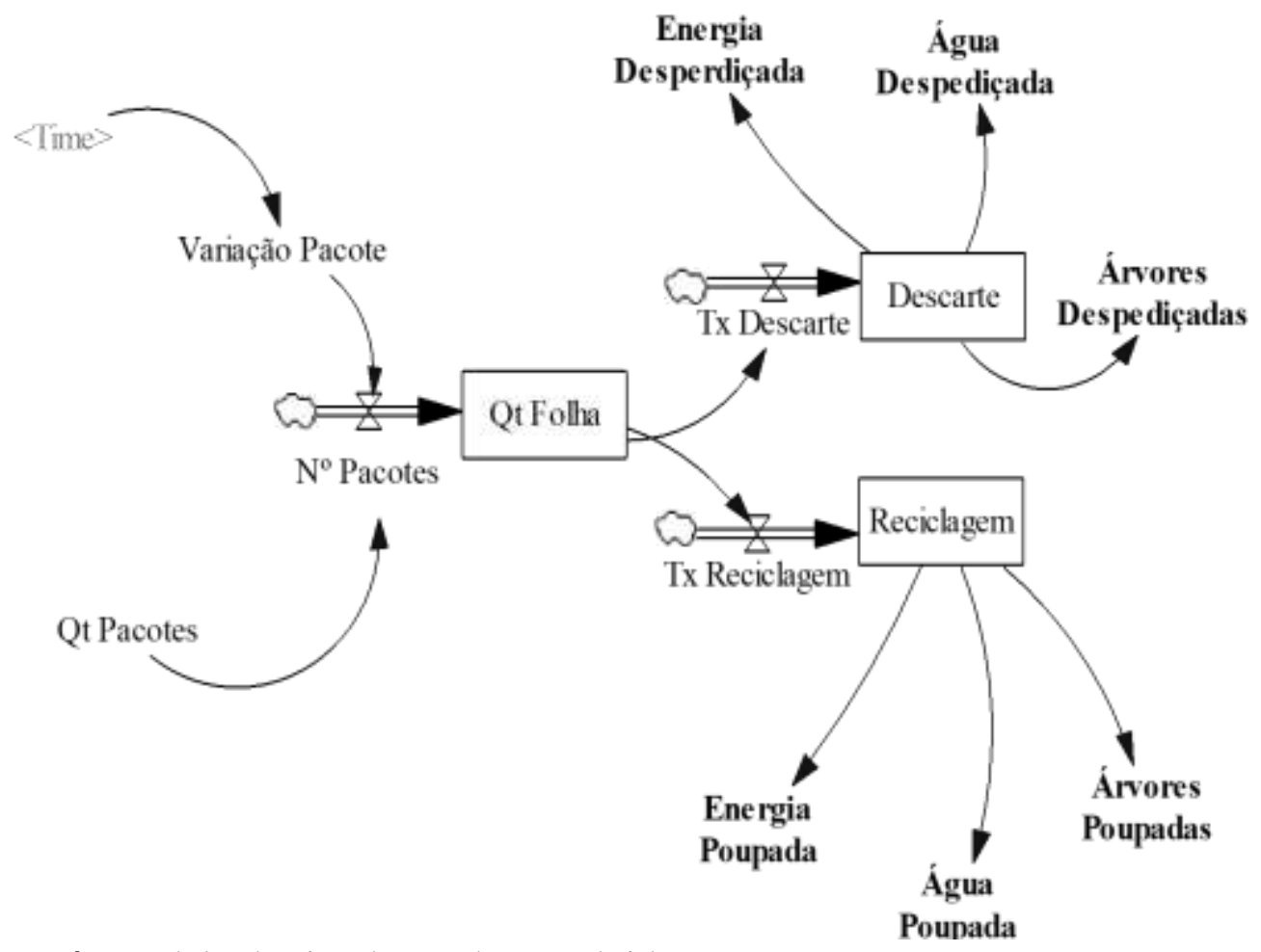

Figura 4: Modelo de simulação desenvolvido.

Fonte: Autores (2018).

Segundo dados da Waste Management (2013), um eucalipto é capaz de produzir vinte mil folhas e onze árvores produzem uma tonelada de papel, sendo que uma folha tem o peso médio de setenta e cinco gramas. A Associação Brasileira Técnica de Celulose e Papel (ABTCP, 2007) afirma que uma tonelada de papel necessita de aproximadamente quarenta mil e quinhentos litros de água para sua fabricação, uma quantia de grande escala se pensássemos em uma produção maciça. Outro detalhe de produção é a energia elétrica consumida, uma tonelada de papel carece de aproximadamente 2,5 $\mathrm{MW} / \mathrm{h}$ de energia elétrica (Waste Management, 2013). Dentre estes dados apresentados brevemente, gerou-se onze equações que estão apresentadas no Figura 5. 
(1) $\mathrm{N}^{\mathrm{o}}$ Pacotes $=$ Qt Pacotes*Variação Pacote

(2) Tx Descarte $=$ Qt Folha*X

(3) Tx Reciclagem = Qt Folha*Y

(4) Reciclagem $=$ Tx Reciclagem

(5) Descarte $=$ Tx Descarte

(6) Energia Poupada $=$ Descarte*0.000188

(7) Água Poupada $=$ Reciclagem $* 3.0375$

(8) Árvores Poupada $=$ Reciclagem $/ 20000$

(9) Energia Desperdiçada $=$ Descarte $* 0.000188$

(10) Água Desperdiçada $=$ Descarte*3.0375

(11) Arvore Desperdiçada $=$ Descarte $/ 20000$

Figura 5: Modelo de equações

Fonte: Autores (2018).

As variáveis expostas no Quadro 2 foram transformadas para a mesma unidade e proporção, já que alguns dados foram encontrados em unidades de massa (toneladas) e outros em unidades de capacidade (litros). Para a modelagem desenvolvida neste estudo foram gerados três cenários conforme exposto na Figura 6. Marcial e Grumbach (2005) citam que as técnicas prospectivas, como a geração de cenários, originaram-se entre os militares durante a segunda Guerra Mundial e foram utilizadas de forma sistemática, principalmente pelos Estados Unidos da América, para apoio a mecanismos de formação de estratégias bélicas. Na França, segundo Godet (2000), esses artifícios eram usados em estudos de prospecção geográfica, a partir desse fato tal método foi utilizado em setores da indústria e agricultura.

\begin{tabular}{|c|c|c|}
\hline & Taxa de descarte & Taxa de reciclagem \\
\hline Cenário Atual & 0.8 & 0.2 \\
\hline Cenário Mediano & 0.5 & 0.5 \\
\hline Cenário Otimista & 0.2 & 0.8 \\
\hline
\end{tabular}

Figura 6: Taxas dos cenários modelados

Fonte: Autores (2018).

A criação dos cenários possibilitou analisar a proposta de diferentes decisões que ficará a critério de aceitação dos gestores responsáveis pela área. Cabe frisar que as taxas foram variadas anualmente conforme apresentado na Figura 6, possibilitando assim, alteração nos fluxos, entradas e saídas do modelo criado. Na próxima seção será apresentado o resultado destas alterações decorrentes do tempo estudado. 


\subsection{Resultados}

Logo após a definição dos três cenários para a experimentação do modelo foram executadas as simulações no software Vensim (Vensim, 2016) em um computador com processador Pentium Core i5 e 8 Gb de memória RAM. O tempo de execução da simulação foi na ordem de milionésimos de segundos. O horizonte de tempo simulado no experimento foi de 8 (oito) anos, entretanto, a configuração dessa variável fica a cargo do projetista/usuário já que a mesma depende da análise a ser realizada.

O modelo apresenta três variáveis de saída - EnergiaDesperdiçada, ÁrvoresDesperdiçadas , ÁguaDesperdiçada, respectivamente - com o objetivo de armazenar os valores acumulados pelo desperdício de recursos naturais já que não serão simulados $100 \%$ de reciclagem. No que se refere às variáveis que estocam os dados referentes à reciclagem do papel existem três variáveis auxiliares, a saber: EnergiaPoupada, ÁrvoresPoupadas, ÁguaPoupada, respectivamente. Os resultados da interação das variáveis do modelo serão expostos a seguir.

A primeira análise feita busca minimizar a utilização de água na produção do papel usado nas folhas. A Figura 7 apresenta duas situações geradas pelo simulador Vensim, onde o lado esquerdo refere-se à água desperdiçada e o lado direito revela a variação da água poupada nos oito anos simulados. O cenário otimista, se aplicado, irá gerar uma economia de, aproximadamente, 122.830 litros de água já o cenário atual irá desperdiçar cerca de 138.000 de litros de água.
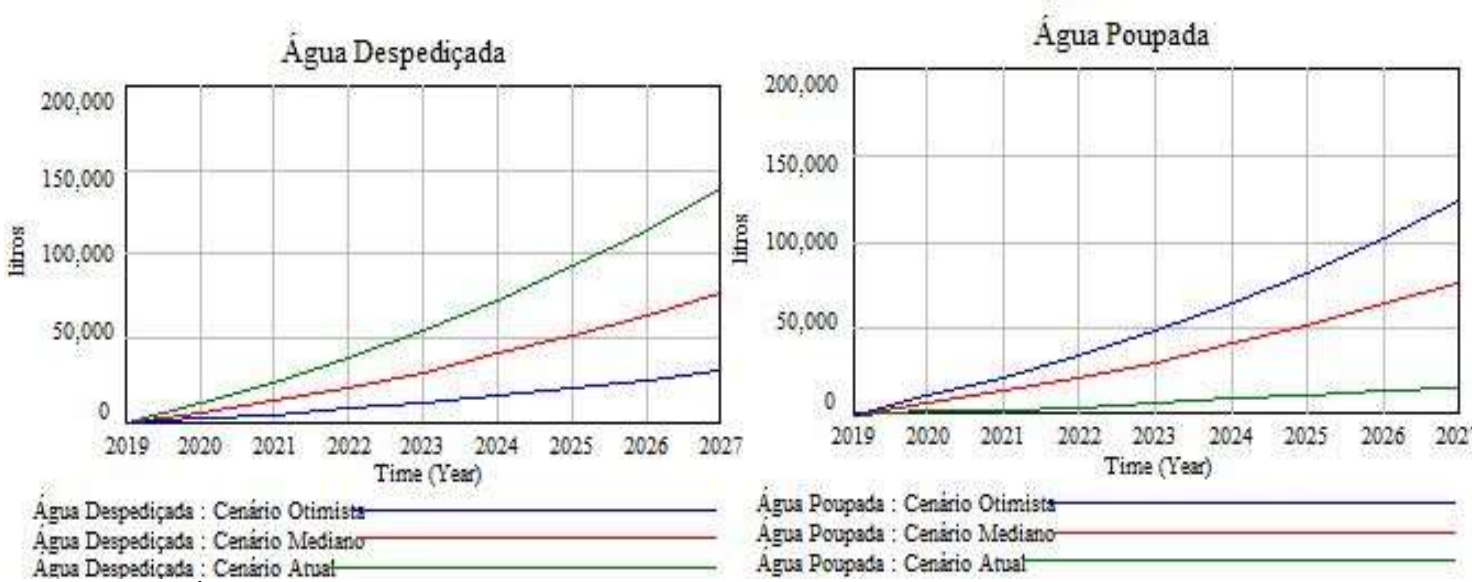

Figura 7: Água desperdiçada versus poupada.

Fonte: Autores (2018). 
Todos os cenários utilizam certa quantidade de água para gerar uma folha. Contudo, a diferença é a quantidade de água desperdiçada, ou seja, enquanto o cenário otimista desperdiça 500.000 litros de água o cenário mediano, por sua vez, irá desperdiçar cerca de 1.000 .000 de litros de água. Outra decisão que poderá ser utilizada pelo modelo tem relação com a energia elétrica. O cenário atual aplicado na IES estudada utilizará em oito anos cerca de $855.000 \mathrm{Kw} / \mathrm{h}$ e enquanto o cenário otimista terá utilizado em 2027 aproximadamente $190.000 \mathrm{Kw} / \mathrm{h}$. Esse fato é apresentado na Figura 8.

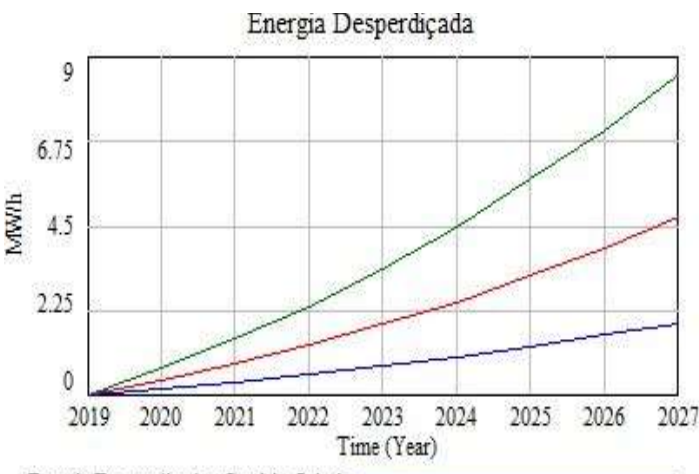

Energia Desperdicada : Cenário Otimista Energia Desperdiçada : Cenário Mediano Energia Desperdiçada : Cenario A tual

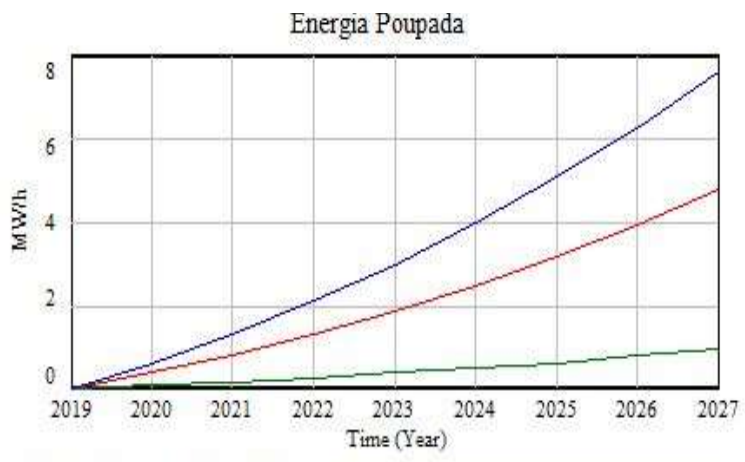

Energia Poupada : Cenário Otimista Energia Poupada : Cenário Mediano Energia Poupada : Cenário Atual

Figura 8: Energia desperdiçada versus poupada.

Fonte: Autores (2018).

O cenário mediano também irá gerar resultados mais sustentáveis em comparação ao cenário atual, ele irá poupar $45.000 \mathrm{Kw} / \mathrm{h}$ a mais e cerca de $30.000 \mathrm{kw} / \mathrm{h}$ que o cenário otimista. Por fim, a última decisão analisada pelos modeladores tem foco no desmatamento, sendo assim, geraram-se cenários buscando diminuir o desmatamento do planeta. O cenário atual necessitará de 2.000.000 de troncos de árvores para fabricar a quantidade de folhas a serem utilizadas pela IES em 8 anos, já o cenário otimista necessitará de 500.000 troncos de árvores. Isso significa uma economia de, aproximadamente, 1.500 .000 troncos de árvores. A diferença extensa representa a grande necessidade de aplicação de decisões mais sustentáveis. Na Figura 9 segue a comparação entre árvores desperdiçadas versus poupadas nos cenários dimensionados. 

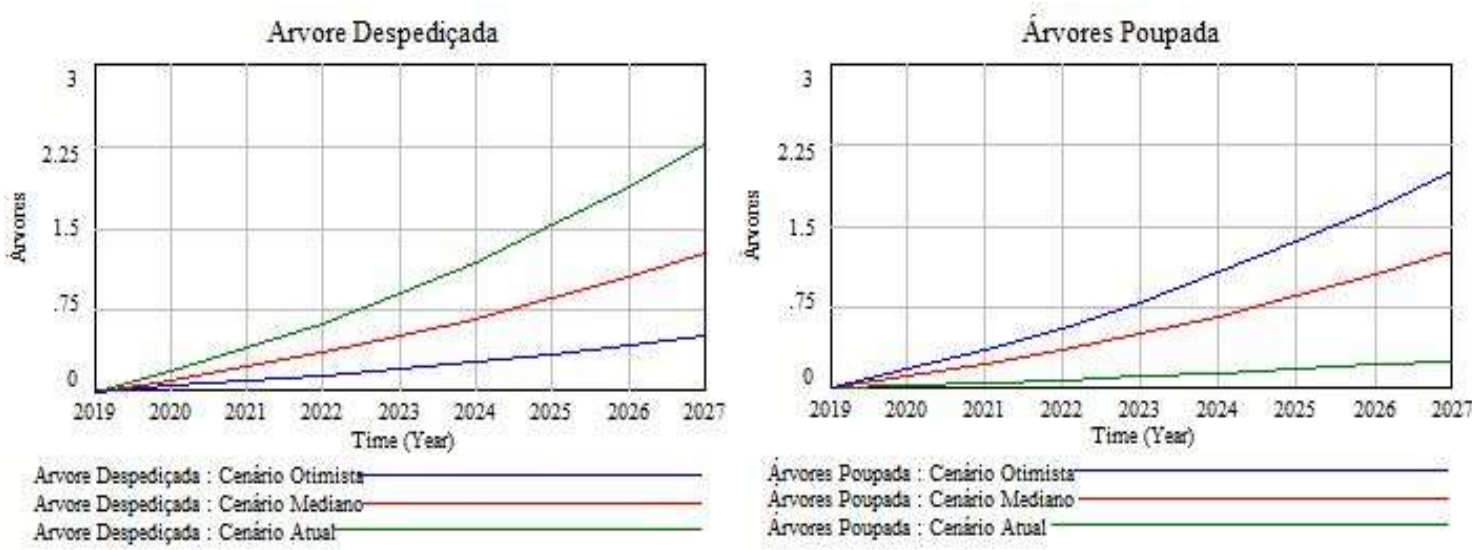

Figura 9: Árvores desperdiçadas versus poupadas.

Fonte: Autores (2018).

Dentre as análises realizadas o cenário otimista apresentou o melhor desempenho pelos dados visualizados comprovando que o uso de folhas recicladas afetará o meio ambiente. Deste modo, as políticas de sustentabilidade se aplicadas poderão ajudar o meio ambiente e diminuir os problemas originados pelo desmatamento, falta de água potável e energia elétrica.

A aplicação do cenário moderado - que é o mais realista - já ofertará um futuro melhor ao planeta, auxiliando na diminuição das catástrofes ambientais que estão aumentando nos últimos anos. Os resultados gerados pelo modelo podem auxiliar a gestão no processo de sensibilização da comunidade no que se refere à importância da reciclagem demonstrando, de forma quantitativa, o quanto pode ser poupado e/ou desperdiçado, em especial, acerca dos recursos como energia, água e o corte de árvores nos cenários simulados no período estudado.

\section{Considerações Finais}

A aglomeração de resíduos sólidos é um problema que atinge todos os cantos do planeta e diversos estudos foram elaborados na tentativa de reduzir o impacto do descarte e acúmulo destes resíduos. Dentre os resíduos sólidos existentes este artigo teve como objeto de análise o papel. Uma proposta seria a reciclagem em maior escala do papel utilizado nas IES públicas do Brasil onde dentre outras vantagens na aplicação desta estratégia estão: a redução do corte de árvores, a preservação de uma boa quantidade de água potável e a redução do consumo de energia elétrica.

No caso do presente estudo, para o desenvolvimento do modelo de simulação, levou-se em conta o conceito que modelos de Dinâmica de Sistemas que são compostos por variáveis de estoque e fluxo, ambas variáveis endógenas. Um dos objetivos centrais da metodologia de 
Dinâmica de Sistemas é ter um modelo que consiga simular o comportamento real. Ou seja, a fonte dos problemas em um sistema seja uma parte inerente do modelo desenvolvido. Deste modo, a metodologia de Dinâmica de Sistemas auxiliou no mapeamento das estruturas do sistema desenvolvido, buscando examinar sua inter-relação em contexto amplo.

Por meio da simulação desenvolvida, a dinâmica aplicada teve como propósito compreender como o sistema analisado evoluiu ao longo do tempo e como as mudanças em suas partes afetaram o seu comportamento. A partir dessa compreensão, foi possível diagnosticar e prognosticar o sistema, além de possibilitar simular mais cenários no tempo. É oportuno destacar que os referidos cenários obtidos neste artigo foram gerados para esse experimento em específico, contudo, o modelo pode ser configurado em conformidade com as necessidades de quem vier a usá-lo, ou seja, trata-se de um modelo aberto e reconfigurável.

Os resultados apresentados foram obtidos através de simulações feitas utilizando para tal o software Vensim. Porém, é possível afirmar que a redução do impacto ambiental gerado para um cenário de 8 anos justificam a aplicação dos resultados gerados pelo modelo. A partir dos resultados gerados pela simulação, os gestores poderão definir as políticas de compras de papel levando em consideração a sustentabilidade ambiental no processo decisório.

No mais, considerando que outras variáveis poderão ser incluídas em um novo modelo, como trabalho futuro pretende-se expandir o modelo aqui apresentado a outras IES. Além disso, sugere-se incluir em uma nova pesquisa os benefícios sociais que podem ser gerados pela reciclagem, entre outros, pode-se citar a questão da geração de emprego e renda aos envolvidos direta e/ou indiretamente em todas as etapas do ciclo. Ademais, outras análises podem vir a ser elaboradas contemplando assuntos de interesse tanto dos gestores ambientais como organizacionais - como no caso do custo de geração da folha reciclada - ou seja, investigações que visem apontar meios que permitam reduzir o consumo de materiais, os custos, ao mesmo tempo, preservando o meio ambiente.

\section{Referências}

Amaral, J. A. A. do (2012). Desvendando sistemas. São Paulo: Edição do Autor.

Amaral, J. A. A., Gonçalves, P., \& Hess, A. (2015). Creating a project-based learning environment to improve project management skills of graduate students. Journal of Problem Based Learning in Higher Education, 3(2), 120-130. 
Andrade, A. L., Seleme, A., Rodrigues, L. H., \& Souto, R. (2006). Pensamento sistêmico: caderno de campo: o desafio da mudança sustentada nas organizações e na sociedade. Porto Alegre: Bookman.

Araújo, S. M. de, Freitas, L. S. de, \& Rocha, V. S. G. (2017). Gestão ambiental: práticas sustentáveis nos campi de uma IFES. Revista de Administração, Contabilidade e Sustentabilidade, 7(3), 36-50.

Associação Brasileira Técnica de Celulose e Papel - ABTCP. (2007). Análise comparativa do desempenho de fábricas de celulose 2007. Estudo Piloto: Curitiba.

Barbieri, J. C. (2007). Gestão ambiental empresarial (2a ed.). São Paulo: Saraiva.

Ceruti, F. C., \& Silva, M. L. N. da. (2009). Dificuldades de implantação de sistema de gestão ambiental (SGA) em empresas. Revista Acadêmica: Ciência Animal, 7(1), 111-119.

Chen, Y. (2011). Green organizational identity: sources and consequence. Management Decision, 49(3), 384-404.

Christmann, P. (2000). Effects of "best practices" of environmental management on cost advantage: the role of complementary assets. Academy of Management Journal, 43(4), 663680.

Falkner, R. (2008). Business power and conflict in international environmental politics. New York: Palgrave Macmillan.

Ferreira Junior, F., \& Santos, O. dos. (2014). Tratamento de fibras secundárias. In: Cherubin, M. J., \& Robusti, C. (Orgs.). Papel. São Paulo: Senai/SP Editora.

Ford, A. (2009). Modeling the environment (2a ed.). Washington: Island Press.

Fundo Mundial para a Natureza - WWW-Brasil. (2017). [Pegada Ecológica Global]. Recuperado em $20 \quad$ Dezembro, $2017, \quad$ de https://www.wwf.org.br/natureza_brasileira/especiais/pegada_ecologica/pegada_ecologica_gl obal/.

Gauto, M., \& Rosa, G. (2013). Química industrial. Porto Alegre: Bookman.

Godet, M. (2000). A "caixa de ferramentas" da prospectiva estratégica. Lisboa: Cadernos do Cepes.

Instituto Gea - Ética e Meio Ambiente. (2017). [O que pode ser reciclado]. Recuperado em 06 Dezembro, 2017, de http://www.institutogea.org.br/lixo/o-que-pode-ser-reciclado/.

Jabbour, A. B. L. S., \& Jabbour, C. C. (2013). Gestão ambiental nas organizações: fundamentos e tendências. São Paulo: Atlas.

Jacobi, P. R. (2015). Meio ambiente, riscos e aprendizagem social. Revista Cadernos de Pesquisa: Pensamento Educacional, 10(26), 346-364. 
Krupp, R., Silva, R. M., \& Vieira, G. B. B. (2017). A Logística reversa de pós-consumo: um estudo de caso na Cooperativa Cootre de Esteio-RS. Revista de Gestão Ambiental e Sustentabilidade, 6(1), 72-86.

Lagarinhos, C. A. F., Tenório, J. A. S. (2013). Logística reversa dos pneus usados no Brasil. Polímeros, 23(1), 49-58.

Leuck, M. F. (2008). Avaliação econômica do impacto de medidas individualizadas de conservação de água em Porto Alegre. Dissertação de mestrado, Universidade Federal do Rio Grande do Sul, Porto Alegre, RS, Brasil.

Lomasso, A. L., Santos, B. R. dos, Anjos, F. A. da S., Andrade, J. C. de, Silva, L. A. da, Santos, Q. R. dos, \& Carvalho, A. C. M. de. (2015). Benefícios e desafios na implementação da reciclagem: um estudo de caso no Centro Mineiro de Referência em Resíduos (CMRR). Revista Pensar Gestão e Administração, 3(2), 1-20.

Lopes, A. A. (2003). Estudo da gestão e do gerenciamento integrado dos resíduos sólidos urbanos no município de São Carlos. Dissertação de mestrado, Universidade de São Paulo, São Carlos, SP, Brasil.

Lourenço, J. C., \& Lira, W. S. (2012). Logística reversa: uma análise comparativa entre três processos reversos de resíduos vítreos. Revista de Administração, Contabilidade $e$ Sustentabilidade, 2(4), 19-34.

Madachy, R. (2008). Software process dynamics. Hoboken: IEEE Press Wiley-InterScience.

Marcial, E. C., \& Grumbach, R. J. S. (2005). Cenários prospectivos: como construir um futuro melhor (3a ed.). Rio de Janeiro: FGV.

Martín-Peña, M. L., Díaz-Garrido, E., \& Sanchez-López, J. M. (2014). Analysis of benefits and difficulties associated with firms' environmental management systems: the case of the Spanish automotive industry. Journal of Cleaner Production, 70, 220-230.

Mello, P. C. B., \& Fonseca, R. (Coord.). (2010). Arte, novas tecnologias e comunicação: fenomenologia da contemporaneidade. São Paulo: Ciantec.

Miranda, R. E. dos S. de. (2008). Impactos ambientais decorrentes dos resíduos gerados na produção de papel e celulose. Monografia de Graduação, Universidade Federal Rural do Rio de Janeiro, Seropédica, RJ, Brasil.

Moura, B. do C. (2006). Logística: conceitos e tendências. Lisboa: Centro Atlântico.

Pereira, A. L., Boechat, C. B., Tadeu, H. F. B., Silva, J. T. M., \& Campos, P. M. S. (2012). Logística reversa e sustentabilidade. São Paulo: Cengage Learning.

Pereira, F. A. de M., Ferraz, S. B., \& Massaini, S. A. (2014). Dimensões de Consciência dos Consumidores no Processo de Reciclagem do Lixo Eletrônico (E-WASTE). Revista Gestão \& Tecnologia, 14(3), 177-202. 
Pidd, M. (2001). Modelagem empresarial: ferramentas para tomada de decisão. Porto Alegre: Artmed.

Rocha, J. C., Rosa, A. H., \& Cardoso, A. A. (2010). Introdução à química ambiental (2a ed.). Porto Alegre: Bookman.

Rodrigues, F. L., \& Cavinatto, V. M. (2003). Lixo: de onde vem? Para onde vai? (2a ed.). São Paulo: Moderna.

Rondón, E. O. O., Murakami, A. E., \& Sakaguti, E. S. (2002). Modelagem computacional para produção e pesquisa em avicultura. Revista Brasileira de Ciência Avícola, 4(1), 199-207.

Rosa, M. R. da, \& Smek, D. J. (2017). Práticas sustentáveis para utilização de recursos de TI na administração pública federal. Revista Gestão \& Tecnologia, 17(3), 267-291.

Rossato, I. F., \& Sens Neto, V. N. (2014). Trabalho de educação ambiental para conscientizar da importância na reciclagem para preservação do meio ambiente. Revista Gestão e Sustentabilidade Ambiental, 3(1), 98-115.

Sanches, C. S. (2000). Gestão ambiental proativa. Revista de Administração de Empresas, 40(1), 76-87.

Santos, J. A., Galdino, C. L., Akabane, G. K., \& Santos, E. B. A. (2015). Matéria-prima gerada da reciclagem de garrafas pet e seus produtos derivados. Revista Metropolitana de Sustentabilidade, 5(2), 3-13.

Shibao, F. Y., Moori, R. G., \& Santos, M. R. dos. (2010, setembro). A logística reversa e a sustentabilidade empresarial. Anais do Seminários em Administração, São Paulo, SP, Brasil, 13.

Simonetto, E. de O., \& Borenstein, D. (2007). A decision support system for the operational planning of solid waste collection. Waste Management, 27(10), 1286-1297.

Simonetto, E. de. O., \& Löbler, M. L. (2014). Simulação baseada em System Dynamics para avaliação de cenários sobre geração e disposição de resíduos sólidos urbanos. Production, 24(1), 212-224.

Souza, M. T. S. de, Paula, M. B. de, \& Souza-Pinto, H. de. (2012). O papel das cooperativas de reciclagem nos canais reversos pós-consumo. $R A E, 52(2), 246-262$.

Tatoutchoup, F. D. (2016). Optimal rate of paper recycling. Forest Policy and Economics, 73, 264269.

Tinoco, J. E. P., \& Kraemer, P. M. E. (2011). Contabilidade e gestão ambiental (3a ed.). São Paulo: Atlas.

Vamberto, O. de S., Lacerda, C. C. de O., Silva, N. E. F., \& Silva, L. de B. (2013). Práticas ecológicas e coleta seletiva na Universidade Estadual da Paraíba. Revista de Administração, Contabilidade e Sustentabilidade, 3(3), 83-98. 
Vensim - Ventana Simulations. (2016). [Vensim simulation software]. Recuperado em 20 Dezembro, 2017, de http://www.vensim.com.

Ventana Systems. (2016). [Vensim Simulation Software]. Recuperado em 10 Fevereiro, 2018, de http://www.vensim.com.

Villela, P. R. C. (2005). [Introdução à dinâmica de sistemas]. Recuperado em 01 Maio, 2018, de http://www.ufjf.br/ciro_barbosa/files/2011/02/ds_parte1.pdf.

Wagner, M. (2005). How to reconcile environmental and economic performance to improve corporate sustainability: corporate environmental strategies in the European paper industry. Journal of Environmental Management, 76(2), 105-118.

Waste Management. (2013). [Recycling facts and tips]. Recuperado em 20 Fevereiro, 2018, de http://www.wm.com/locaton/california/north-valley/willows/facts.jsp.

Wilson, C. D. H., Williams, I. D., \& Kemp, S. (2012). An evaluation of the impact and effectiveness of environmental legislation in small and medium-sized enterprises: experiences from the UK. Business Strategy and the Environment, 21(3), 141-156. 